
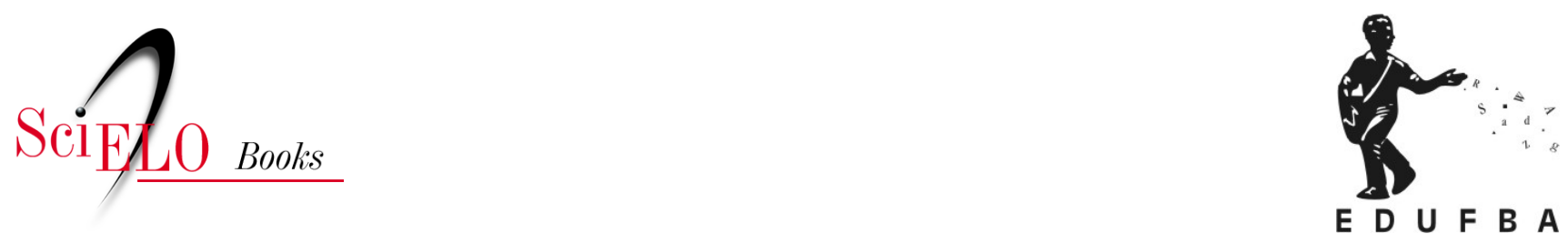

\title{
Brasil \\ na vanguarda latino-americana das políticas de ação afirmativa baseadas em raça e dos recenseamentos com recorte racial
}

\author{
Tanya Katerí Hernández \\ Arivaldo Santos de Souza \\ Luciana Carvalho Fonseca \\ (Tradutores)
}

\section{SciELO Books / SciELO Livros / SciELO Libros}

HERNÁNDEZ, T.K. Brasil: na vanguarda latino-americana das políticas de ação afirmativa baseadas em raça e dos recenseamentos com recorte racial. In: Subordinação racial no Brasil e na América Latina: o papel do Estado, o Direito Costumeiro e a Nova Resposta dos Direitos Civis [online]. Translated by Arivaldo Santos de Souza and Luciana Carvalho Fonseca. Salvador: EDUFBA, 2017, pp. 137-154. ISBN: 978-85-232-2015-0. https://doi.org/10.7476/9788523220150.0008.

All the contents of this work, except where otherwise noted, is licensed under a Creative Commons Attribution 4.0 International license.

Todo o conteúdo deste trabalho, exceto quando houver ressalva, é publicado sob a licença Creative Commons Atribição $\underline{4.0}$. 


\section{Brasil: na vanguarda latino- americana das políticas de ação afirmativa baseadas em raça e dos recenseamentos com recorte racial}

A inexistência de dados sobre raça em muitos países latino-americanos dificulta não só a capacidade de reunir sistematicamente estatísticas sobre um grupo social que demonstre a sua exclusão racial, mas também a capacidade de pressionar efetivamente por políticas de ação afirmativa baseadas em raça para melhorar a situação de exclusão racial. Até agora, a criação de programas e políticas de ação afirmativa na América Ibérica tem sido bastante modesta.

A Colômbia é o único país que destina assentos no Poder Legislativo a afrocolombianos, na Câmara dos Deputados (em vez de apenas para mulheres, como em muitos países latino-americanos, como Argentina, Bolívia, Colômbia, Costa Rica, República Dominicana, Equador, México, Panamá, Paraguai e Peru). (HTUN, 2003) Mais especificamente, a Constituição colombiana reconhece a representação política de afrodescendentes e populações indígenas na Câmara dos Deputados e no Senado. ${ }^{1}$ Além disso, em 1996, a Colômbia criou um programa de créditos educativos para comunidades afro-colombianas. (COLÔMBIA, [20--]) Esse programa consiste na alocação de créditos 
universitários para afro-colombianos em troca de prestação de serviços: "serviço comunitário, social, acadêmico, conforme o projeto apresentado por ocasião da candidatura, que é garantida por uma organização de base”. Os requisitos para ser beneficiado pelo programa são possuir um certificado de participação em uma comunidade afro-colombiana, excelência acadêmica, hipossuficiência econômica e apresentação de um projeto para resolver problemas ou necessidades da comunidade de origem. (LEÓN; HOLGUíN, 2004)

Além do mais, várias universidades colombianas, tanto públicas como privadas, criaram programas especiais de admissão para minorias étnicas, incluindo afro-colombianos. (LEÓN; HOLGUíN, 2005, p. 208-211; LEÓN; HOLGUÍN, 2004, p. 60) As vagas reservadas variam de duas a cinco por curso. (PASCALE, 2010, p. 42) Os programas de ação afirmativa, primeiro, começaram admitindo estudantes indígenas, em seguida foram ampliados para incluir colombianos afrodescendentes. (HEREDIA et al., 2009)

De modo similar, no Equador, o governo tem feito planos para estabelecer uma cota de $10 \%$ para estudantes afro-equatorianos e indígenas em instituições de ensino médio públicas e privadas. Isso porque o artigo 11.2 da Constituição equatoriana declara que "O Estado adotará ações afirmativas para promover igualdade em favor daqueles que se encontram em situação de desigualdade”. (EQUADOR, 2008) O governo também planeja estabelecer cotas para professores e pesquisadores em universidades. (PLAN PLURINACIONAL, 2009, p. 35) De modo mais limitado, o governo, juntamente com a Universidade Andina Simón Bolivar, criou um programa no qual 15 advogados afro-equatorianos receberam bolsas para uma especialização em direitos humanos, que terá ênfase em comunidades afrodescendentes. (15 ABOGADOS..., 2011) Outro programa governamental ofereceu 10 bolsas para estudantes afro-equatorianos que querem fazer cursos de mestrado. (BECAS, 2011) No campo dos empregos públicos, o governo equatoriano também planeja uma política de ação afirmativa para contratação em vários órgãos governamentais. ${ }^{2}$

O governo equatoriano também fez acordos com seis governos locais diferentes para construir casas especialmente para afro-equatorianos. Por exemplo, em um acordo com a entidade subnacional de Canton Ibárra, o governo se comprometeu em investir 700 mil dólares para a implementação de um programa 
que criaria 250 unidades habitacionais para afrodescendentes da região, e o Canton Ibárra seria responsável pela implementação do programa. Ainda que 700 mil dólares possam parecer um valor modesto, deve-se observar que o custo médio da construção de uma unidade habitacional de $100 \mathrm{~m}^{2}$ no Equador é de 36 mil dólares.

Em Honduras, o governo criou um programa de bolsas para estudantes afro-hondurenhos que querem continuar o ensino médio e ingressar na universidade. ${ }^{3}$ No Uruguai, o Ministério da Educação e Cultura dispõe de um fundo que oferece bolsas para estudantes afro-uruguaios. Há também bolsas de pós-graduação, como a bolsa Carlos Quijano, voltada para estudantes afro-uruguaios. (PASCALE, 2010, p. 44)

Em resumo, a disponibilidade de programas de ação afirmativa na América Latina é bastante limitada se comparada com a dos Estados Unidos, onde um número incontável de empregadores, universidades e órgãos públicos têm políticas de ação afirmativa. Os primeiros passos para considerar a ação afirmativa de maneira mais ampla na América Latina têm se dado na forma de organismos governamentais criados para auxiliar a promoção da igualdade. Ouvidores públicos especialmente voltados para questões de racismo podem ser encontrados em todos os países latino-americanos, exceto em El Salvador, Chile e Paraguai. Por exemplo, na Venezuela, a Comissão Presidencial para a Prevenção e Eliminação de Todas as Formas de Discriminação Racial e Outras Distinções no Sistema Educacional Venezuelano é responsável por promulgar políticas antidiscriminatórias. Contudo, até agora, a única norma aprovada foi um decreto declarando 10 de maio o dia do afro-venezuelano. (VENEZUELA, 2005)

Ainda que tal tipo de legislação simbólica certamente seja importante para chamar a atenção para a existência e a difícil situação dos afrodescendentes, há uma carência na América Latina de programas que lidem diretamente com a questão das instituições que barram afrodescendentes devido a preconceitos e estereótipos raciais. Portanto, a Venezuela é um exemplo emblemático da adoção incipiente de ações afirmativas na América Latina. Em contraste, o Brasil se destaca como a nação latino-americana com o maior número de políticas de ações afirmativas voltadas para afrodescendentes.

3 Decreto ejecutivo 09, 2007 (Honduras). 


\section{O debate sobre ação afirmativa no Brasil}

Há várias razões para o Brasil ser o país latino-americano que mais adota ações afirmativas baseadas em raça. Os movimentos afro-brasileiros de justiça social foram ativos participantes da Conferência Mundial das Nações Unidas contra o Racismo em 2001. A atenção pública que a conferência ofereceu para os assuntos de igualdade racial permitiu que ONGs exercessem pressão sobre o governo brasileiro. Além disso, a ênfase da conferência no apoio às ações afirmativas, feito pelo texto da Convenção Internacional para a Eliminação de Todas as Formas de Discriminação Racial, proporcionou fundamentos jurídicos para uma ação do Poder Executivo. O artigo $1^{\circ}$, seção 4, da convenção, da qual o Brasil é um dos signatários, estabelece que

Não serão consideradas discriminação racial as medidas especiais tomadas com o único objetivo de assegurar o progresso adequado de certos grupos raciais ou étnicos ou de indivíduos que necessitem da proteção que possa ser necessária para proporcionar a tais grupos ou indivíduos igual gozo ou exercício de direitos humanos e liberdades fundamentais, contanto que tais medidas não conduzam, em consequência, à manutenção de direitos separados para diferentes grupos raciais e não prossigam após terem sido alcançados os seus objetivos.

O então presidente Fernando Henrique Cardoso foi especialmente receptivo à questão das ações afirmativas devido ao seu próprio trabalho intelectual como um proeminente sociólogo que lidou com a questão da desigualdade racial no Brasil. (HTUN, 2004, p. 60-89) Por exemplo, como sociólogo, o presidente Fernando Henrique Cardoso escreveu, juntamente com Octavio Ianni, o livro Cor e mobilidade social em Florianópolis: aspectos das relações entre negros e brancos numa comunidade do Brasil Meridional. (CARDOSO; IANNI, 1960)

Em consequência, o Brasil começou a instituir políticas de ação afirmativa em 2001, quando o Ministério da Agricultura determinou que 20\% dos seus servidores fossem negros, que $20 \%$ dos empregados das empresas contratadas pelo ministério fossem negros e que outros $20 \%$ fossem mulheres. (RACUSEN, 2004, p. 811-812) Depois disso, o Supremo Tribunal Federal (STF) e outros órgãos públicos também instituíram políticas de ação afirmativa. (RACUSEN, 2004, p. 812-813) O programa de ações afirmativas do STF estabeleceu uma cota de $20 \%$ de afrodescendentes para as empresas contratantes com o órgão. (CESAR, 2003, p. 28) O programa de ação afirmativa do Ministério 
da Justiça estabeleceu que $20 \%$ das posições de direção superior deveriam ser preenchidas por afrodescendentes. A administração pública federal estabeleceu o Programa Nacional de Ação Afirmativa, que previa uma série de metas percentuais para a participação de afrodescendentes na administração pública, além de obrigações similares para as empresas contratantes com o poder público federal. Por sua vez, um programa do Instituto Rio Branco passou, em 2001, a oferecer bolsas voltadas à preparação de afrodescendentes aos estudos para o concurso de admissão à carreira diplomática. Além disso, em 2002, a Lei n. ${ }^{\circ} 10.558$ criou o Programa Diversidade na Universidade, no âmbito do Ministério da Educação, com a finalidade de implementar e avaliar estratégias para a promoção do acesso ao ensino superior de pessoas pertencentes a grupos socialmente desfavorecidos, especialmente dos afrodescendentes e dos indígenas brasileiros. O programa incluía financiamento para entidades públicas e privadas, sem fins lucrativos, que atuassem na área de educação e que viessem a desenvolver projetos inovadores para atender a finalidade do programa.

Assim como o governo federal brasileiro, os governos locais começaram a instituir programas de ação afirmativa. Por exemplo, em junho de 2011, o estado do Rio de Janeiro aprovou um decreto instituindo a reserva de $20 \%$ das vagas para negros e pessoas de ascendência indígena nos concursos públicos do estado. (RIO DE JANEIRO, 2011) Importante salientar que enquanto grande parte do discurso público no Brasil confunde o conceito de ação afirmativa com a adoção de cotas, na realidade, os programas de ação afirmativa existentes variam em seu conteúdo e estrutura. (HERINGER, 2004, p. 55-86) Em outras palavras, nem todos os programas de ação afirmativa no Brasil se materializam em forma de cotas.

Ainda mais controversa tem sido a implementação direta de programas de ação afirmativa baseados em raça no ensino superior, aos quais a maioria dos ministros de educação tem se oposto. (DZIDZIENYO, 2005, p. 137-155, 147) Em 2000, a Universidade do Estado do Rio de Janeiro (UERJ) instituiu cotas diretas de $40 \%$ para os estudantes negros e $10 \%$ para estudantes com deficiência. (RIO DE JANEIRO, 2000, 2001) A política de ação afirmativa foi contestada primeiro perante o STF, por uma associação de instituições particulares de ensino (Confenen), como uma violação à provisão constitucional de proporcionalidade no exercício da discrição legislativa (razoabilidade). (RACUSEN, 2004, p. 816) Essa ação judicial ficou prejudicada quando a Assembleia Legislativa do Rio de Janeiro revisou a política, em 2003, para estabelecer um número mais 
limitado de cotas, $20 \%$, para pessoas autodeclaradas negras, $20 \%$ para estudantes de escolas públicas e 5\% para pessoas portadoras de deficiência e indígenas. (RIO DE JANEIRO, 2003) Além disso, todos os estudantes admitidos via a política de cotas deveriam ter um perfil econômico específico. (RACUSEN, 2004, p. 816-817) Após as alterações, a política de ação afirmativa foi novamente contestada judicialmente juntamente com as políticas de ação afirmativa da Universidade de Brasília (UnB), da Universidade Federal do Rio Grande do Sul e da Universidade Estadual do Norte Fluminense. Apenas no caso das duas universidades fluminenses, mais de 300 candidatos descontentes ajuizaram ações contra as políticas de ação afirmativa. (RACUSEN, 2004, p. 815)

Além do mais, 114 acadêmicos assinaram um manifesto, em 2006, se opondo à ação afirmativa baseada em raça, considerando-a inconstitucional e um meio de promover conflito e intolerância. (OSAVA, 2006) Poucos dias depois, 330 intelectuais e representantes de movimentos sociais assinaram uma resposta intitulada "Manifesto em Favor das Leis de Cotas e do Estatuto da Igualdade". Os documentos foram amplamente discutidos na mídia brasileira e o debate continuou, como indica uma pesquisa nacional datada de 2008, sugerindo que $62 \%$ dos brasileiros acreditam que as políticas são essenciais, enquanto outros $53 \%$ acreditam que os programas são humilhantes e $62 \%$ pensam que as políticas podem causar racismo. (GOIS, 2008) Considerando que uma pessoa poderia responder a mais de uma questão, o resultado sugere que muitos brasileiros apresentam um conflito interno sobre o uso de ações afirmativas baseadas em raça. O discurso contrário à ação afirmativa tem sido tão virulento que mesmo alguns dos primeiros beneficiários das políticas demonstram ambivalência na defesa da política. (GONZÁLEZ, 2010, p. 123-138) Como resultado, o STF realizou uma audiência pública em março de 2010 para reunir informação de pessoas com experiência e conhecimento técnico na área de ações afirmativas.

A ação perante o STF argumentou que o sistema de cotas violava o princípio constitucional da igualdade perante a lei prevista no artigo $5^{\circ}$ da Constituição brasileira de 1988, segundo o qual "Todos são iguais perante a lei, sem distinção de qualquer natureza, garantindo-se aos brasileiros e aos estrangeiros residentes no país a inviolabilidade do direito à vida, à liberdade, à igualdade, à segurança e à propriedade”. O argumento foi o de que os estudantes brancos tiveram sua admissão negada, mas marcaram mais pontos nas provas de admissão que candidatos que foram aceitos pelo sistema de cotas, portanto os estudantes brancos teriam sido tratados de maneira desigual. (BRASIL, 2010b) Também é 
importante notar que todas as alegações dos autores afirmavam inexistir práticas racistas institucionalizadas e chanceladas pelo Estado no Brasil (como a segregação da legislação Jim Crow nos Estados Unidos) tornando desnecessária a adoção de ações afirmativas no Brasil, sendo a implementação de ações afirmativas uma imposição racista. Por exemplo, na ação movida contra o programa de ações afirmativas da Universidade de Brasília, o autor questionava "se a implementação de um Estado racializado ou um racismo institucionalizado, como o praticado nos Estados Unidos, África do Sul ou em Ruanda, seria adequado para o Brasil.” (BRASIL, 2009) As alegações, como um todo, reforçavam que o argumento do ideal de democracia racial deve ser preservado em um país tão miscigenado racialmente, cujas designações raciais são tão difíceis de administrar. (SILVA, 2009) Nessa narrativa, o papel histórico do Estado como facilitador da exclusão racial e o papel do direito costumeiro de regulação racial estão completamente ausentes.

Parte da peça do recurso apresentado ao STF lançava mão do voto de um desembargador do Tribunal de Justiça do Rio de Janeiro, de maio de 2009, o qual declarava a lei de ação afirmativa do Rio de Janeiro inconstitucional, com a justificativa firmemente calcada na ultrapassada noção de ser o Brasil uma democracia racial. Especificamente, o voto declarava que o sistema de cotas criava privilégios para uma parte da população brasileira, constituída de pessoas irreversivelmente mestiças, e privilégio no mais alto ponto do processo educacional do país, que são as universidades. Abre-se a possibilidade de que, em um país onde a mistura racial é a regra, surja, por força de lei, um apartheid que não existe no Brasil. (RIO DE JANEIRO, 2009a)

Para esse juiz, assim como para boa parte da elite branca, a rejeição frontal às ações afirmativas está firmemente enraizada na premissa de que a exclusão racial não é parte da cultura brasileira, e que a ação afirmativa criará a segregação que atualmente existe em países, como os Estados Unidos, onde são usadas ações afirmativas.

Porém, não estava claro se tais perspectivas seriam acolhidas. Quando a política de ação afirmativa da Universidade do Estado do Rio de Janeiro foi analisada em segunda instância, o resultado no tribunal foi de 15 votos contra e seis a favor da constitucionalidade da política. (RIO DE JANEIRO, 2009b) Em 19 de março de 2012, o STF arquivou o recurso porque a norma atacada havia sido revogada por uma nova lei de ação afirmativa em 2008, a qual limitou a duração do programa em 10 anos. (BRASIL, 2012a) 
Ainda mais importante, em 26 de abril de 2012, o STF proferiu a decisão que declarava constitucional a política de ação afirmativa da Universidade de Brasília. (BRASIL, 2012b) Em uma decisão unânime, a corte afirmou que, para o país efetivar o princípio da igualdade, as políticas de ação afirmativa são uma importante obrigação e responsabilidade social do Estado, porque a Constituição requer a reparação das perdas impostas aos afro-brasileiros no passado. Além do mais, apenas uma semana depois, a corte também confirmou a constitucionalidade do Programa Universidade para Todos (ProUni), que oferece bolsas para estudantes afrodescendentes de famílias de baixa renda para cursarem universidades privadas. (BRASIL, 2012c) Com essas duas decisões, o STF afirmou a prioridade constitucional de reduzir as desigualdades sociais e o uso de ações afirmativas como uma importante ferramenta de integração social.

Ademais, com o passar do tempo, um número crescente de brasileiros e beneficiários do programa começaram a ver as ações afirmativas como algo positivo. De fato, em uma pesquisa de 2010, 85,4\% dos candidatos negros e indígenas declararam que estavam de acordo com o sistema de cotas. (VESTIBULAR UERJ, 2010) Em contraste, cinco anos antes, apenas 66,8\% dos candidatos a cotistas declararam que a política de ação afirmativa era positiva. (TREVIÑO GONZÁLEZ, 2010, p. 127)

Especialmente reveladora é uma pesquisa de 2010 sobre as atitudes em relação às ações afirmativas, que identificou o percentual da população brasileira que se opõe às ações afirmativas. Na pesquisa de 2010 realizada pelo Americas Barometer, descobriu-se que um alto percentual de brasileiros acredita que reservar lugares nas universidades para afrodescendentes é justo. De fato, dentre os $66,2 \%$ dos que concordam, $45 \%$ "concordam bastante". Dentre os $27,4 \%$ que desaprovam, apenas 18\% "desaprovam bastante". Os 6,5\% restantes não aprovam nem desaprovam. Entretanto, a minoria que "desaprova bastante” é majoritariamente branca, tem ensino superior e é bastante ativa na mídia e no discurso público. (SMITH, 2010) Assim, enquanto a mídia brasileira tem oferecido bastante espaço para as vozes brancas contrárias (e universitárias) criticarem as ações afirmativas, na verdade elas representam uma pequena minoria da população. De fato, mais de dois terços dos brasileiros, conforme o Americas Barometer de 2010, que apoiam as ações afirmativas baseadas em raça, pertencem a todas as raças e afiliações políticas.

Isso explica o porquê de as políticas de ação afirmativa nas universidades continuarem a proliferar de várias formas, a despeito da recusa do Congresso 
Nacional em incluir políticas de ação afirmativa no Estatuto da Igualdade Racial. (BRASIL, 2003) Em agosto de 2010, pelo menos, 80 universidades públicas já haviam adotado políticas de ação afirmativa. As estruturas dos programas variam. (RACUSEN, 2009; CORREA, 2008, p. 6-39) Alguns programas são voltados apenas para estudantes afro-brasileiros oriundos de escolas públicas de ensino médio, como uma maneira de atingir os estudantes afro-brasileiros mais necessitados. Outros programas reservam vagas para estudantes oriundos de escolas públicas de ensino médio de qualquer raça, assim estabelecendo reservas conforme a densidade demográfica proporcional de cada grupo na região. Outra variação reserva vagas para estudantes afro-brasileiros oriundos de escolas de ensino médio públicas ou privadas e há outra variação que reserva vagas para estudantes de escolas públicas de qualquer raça. Finalmente, algumas universidades atribuem pontos extras ao resultado dos exames de admissão de candidatos afro-brasileiros e também para estudantes oriundos de escolas públicas de ensino médio.

Ao considerar o contexto de programas de ação afirmativa em universidades públicas, é importante notar que, ao contrário dos Estados Unidos, onde muitas Instituições de Ensino Superior (IES) privadas são consideradas mais prestigiosas que, com algumas exceções, qualquer universidade pública, as instituições públicas de ensino superior brasileiras estão em alta conta na consideração dos brasileiros, em oposição à maioria das universidades privadas. (TELLES, 2004, p. 124-159) Tanto as universidades públicas gratuitas como as universidades particulares pagas realizam seu próprio processo seletivo, o vestibular. (TELLES, 2004, p. 159; JOHNSON, 2003, p. 2-3) Tradicionalmente, no Brasil, o ingresso na universidade baseou-se apenas no exame do vestibular e as notas do ensino médio eram completamente desconsideradas. Por haver uma concorrência maior para um número reduzido de vagas, alguns alunos, normalmente aqueles com mais recursos financeiros, pagam por um ano de curso preparatório para o vestibular (cursinhos). (JOHNSON, 2003, p. 2-3) O vestibular tem o objetivo de testar o conhecimento substancial de todos os anos de estudo, porém é comum o vestibular testar conteúdo que não foi ensinado nas escolas públicas de ensino fundamental e médio. (JOHNSON, 2003, p. 3; CESAR, 2003, p. 294-295)

Consequentemente, as melhores universidades, ou seja, as públicas, são frequentadas desproporcionalmente por brasileiros brancos cujos pais pagaram pelas melhores escolas na formação básica e média. (TELLES, 2004, p. 124) 
A maioria dos afrodescendentes, que tem recursos limitados, é excluída das universidades públicas de elite e relegada a pagar por escolas privadas ou a parar de estudar. (TELLES, 2004, p. 124; GUIMARÃES, 2003, p. 75-77) Como resultado, no ano de 2010, o Ministério da Educação divulgou que apenas 2\% de todos os estudantes universitários no país eram negros. (CARVALHO, 2001, p. 13-30, 17) Ainda pior, a representatividade de afro-brasileiros era praticamente nula em programas acadêmicos de elite, como medicina e direito. Grupos afrodescendentes de defesa da justiça social criaram cursinhos para ajudar na preparação de estudantes excluídos, e também criaram uma universidade para negros - Faculdade Zumbi dos Palmares (FAZP) -, uma vez que os mesmos acreditam que, sozinhos, os estudantes negros não conseguirão superar as deficiências do ensino público de má qualidade, o que acarreta sua exclusão do ensino superior. (NASCIMENTO, 1999) A política desse padrão demográfico no ingresso à universidade foi o que incentivou os movimentos negros a reivindicarem políticas de ação afirmativa nas universidades. (TELLES, 2004, p. 59, 253)

O fato de o debate público sobre programas de ação afirmativa baseados em raça ter enfrentando resistência difere da facilidade com que as ações afirmativas de gênero foram introduzidas no país alguns anos antes. (HTUN, 2004) Em 1995, o Brasil adotou cotas para mulheres no sistema eleitoral. O artigo 11 da Lei $\mathrm{n}^{\circ}$ 9.100/95 estabeleceu que, pelo menos, 20\% dos candidatos nas eleições municipais legislativas deveriam ser mulheres. Já a Lei nº 9.504/97 estabeleceu uma cota de $25 \%$ para as candidaturas a cargos no legislativo estadual e federal. Com mais de uma década de experiência com tais políticas de ação afirmativa para mulheres, o discurso público nunca caracterizou essas políticas como uma forma de discriminação inconstitucional. Assim, fica evidente que a objeção da elite brasileira às políticas de ação afirmativa baseadas em raça não é uma objeção às ações afirmativas propriamente, mas à natureza racial dessas ações.

Isso também é enfatizado pelo fato de que outras políticas de ação afirmativa não baseadas em raça não causaram discórdia da opinião pública. Programas de ação afirmativa voltados para filhos de fazendeiros e para deficientes foram criados antes das políticas baseadas em raça. Por exemplo, a Lei n ${ }^{0} 5.465 / 68$ instituiu cotas para proporcionar acesso de filhos de fazendeiros à educação superior. (CESAR, 2003, p. 26-32) Para os portadores de deficiência, a Constituição Federal de 1988, artigo 37, VIII, estabelece que a lei reservará um percentual dos cargos e empregos públicos para as pessoas portadoras de deficiência e definirá os critérios de sua admissão. A implementação desse dispositivo 
resultou em várias leis que determinam cotas para pessoas com deficiência no serviço público (Lei n ${ }^{\circ} 8.112 / 90$ ) e no setor privado (Lei n ${ }^{\circ} 8.213 / 91$ ).

Mesmo aqueles que, em princípio, supostamente apoiam programas de ação afirmativa baseados em raça questionam se eles podem ser implementados adequadamente em um país de pessoas "miscigenadas", que possuem identidades raciais fluidas e ambíguas. A preocupação com reivindicações fraudulentas feitas por brasileiros brancos foi levada em conta por ocasião da estruturação de programas de ação afirmativa voltados para candidatos que se autodeclarassem negros, uma vez que "a categoria negro tende a intimidar os oportunistas". (BERNARDINO-COSTA, 2007, p. 281-296, 283) A lógica é que, enquanto o discurso de democracia racial brasileira romantiza a noção de conexões remotas com ancestrais africanos, não diminui as associações pejorativas com uma identidade negra. Apesar disso, a questão das reivindicações fraudulentas existe e foi enfrentada de várias formas, que incluem a solicitação de documentação oficial com dados raciais, solicitação de fotografias para verificar a identidade racial, entrevistas com os candidatos, verificação da renda familiar e uso de informações indiretas sobre raça oriundas das escolas de educação básica frequentadas. (RACUSEN, 2009)

Por sua vez, críticos das ações afirmativas questionam a eficácia dos programas e alegam que irão reduzir a qualidade do ensino universitário. O subtexto explícito é que a ação afirmativa é uma importação imperialista desastrosa que não pode ser aplicada efetivamente em um contexto racial latino-americano, como o brasileiro. (BOURDIEU; WACQUANT, 2002, p. 15-33) Em outras palavras, a história racial da legislação Jim Crow dos Estados Unidos e a consequente estrutura racial rígida são tão estranhas ao contexto latino-americano que a "ação afirmativa estadunidense" não tem lugar no Brasil nem em qualquer outro lugar da América do Sul. Essa crítica ignora a cumplicidade histórica dos Estados latino-americanos por meio do direito costumeiro de regulação racial e chega ao ponto de situar a América Latina como uma região "racialmente inocente" e onerada excessivamente com uma reivindicação por justiça racial descabida.

Entretanto, não somente os gestores brasileiros têm encontrado seus próprios mecanismos para administrar programas de ação afirmativa baseados em raça, como também pesquisas mostram que os resultados dos estudantes cotistas demonstram que os programas são um sucesso. Por exemplo, um estudo dos resultados dos estudantes na Universidade Estadual de Campinas (Unicamp) descobriu que estudantes que cresceram em situação socioeconômica e educacional desvantajosa tiveram desempenho relativamente melhor na universidade 
do que aqueles de níveis socioeconômico e educacional mais alto. (PEDROSA et al., 2007, p. 1-20) O estudo concluiu que a necessidade de trabalho duro ao lutar por mais oportunidades (como estudar para o vestibular mesmo sem preparação adequada no ensino médio das escolas públicas) cria uma "resiliência acadêmica" que melhora o desempenho, uma vez que o estudante é admitido na universidade. (PEDROSA et al., 2007, p. 13) Na Unicamp, o programa de ação afirmativa aloca pontos adicionais para o exame de admissão com base na origem educacional dos estudantes (nesse caso, afrodescendentes pobres predominam) e na condição de ser negro ou indígena. A "resiliência acadêmica" dos estudantes menos privilegiados foi manifestada diretamente nas maiores notas dos estudantes cotistas logo depois do primeiro ano de estudos em 31 dos 35 cursos de graduação. No todo, o desempenho relativo dos estudantes cotistas foi maior em 48 dos 55 cursos.

De modo similar, na UnB, onde $20 \%$ das vagas são reservadas para estudantes negros, dois terços ou mais dos cursos não apresentaram significativas diferenças entre os estudantes cotistas e os não cotistas. (VELLOSO, 2009, p. 621-644) De fato, na turma de 2005, os estudantes cotistas tinham notas mais altas em $55 \%$ dos 33 cursos. Em 2008, foi observado que estudantes cotistas negros em 27 cursos da UnB tinham notas mais altas que os outros estudantes da universidade. (CARDOSO, 2008) O estudo dos estudantes da UnB apontou que essa foi uma tendência também observada em outras universidades brasileiras. De fato, os estudantes cotistas que se matricularam em 2003 na Universidade Estadual do Norte Fluminense (UENF) tinham notas comparáveis aos outros estudantes e, em pelo menos cinco cursos, as notas eram superiores. (BRANDÃO; DA MATTA, 2007, p. 46-80) Por ocasião do vestibular de 2003, o programa de ações afirmativas reservou vagas para estudantes oriundos de escolas públicas, negros e indígenas.

Na Universidade Federal da Bahia (UFBA), os estudantes, cotistas e não cotistas, dos cursos mais prestigiosos e concorridos (como direito e medicina) tiveram desempenho semelhante. (QUEIROZ; SANTOS, 2006, p. 717-737) O programa de ação afirmativa das UFBA reserva vagas para estudantes oriundos de escolas públicas, negros e indígenas. Além disso, há vagas destinadas a estudantes brancos oriundos de escolas públicas. Quando há vagas, estudantes negros oriundos de escolas particulares também podem participar. Em 11 dos 18 cursos mais concorridos da UFBA, $61 \%$ dos estudantes cotistas obtiveram notas maiores ou iguais às notas dos demais estudantes.

De modo similar, um estudo da UERJ mostrou que na primeira turma de estudantes de medicina que contava com cotistas, graduados em 2010, não havia 
diferenças de desempenho acadêmico, desistência e sucesso nos exames de admissão aos programas de residência entre os cotistas e os não cotistas. (VIEIRA, 2011) O programa de ação afirmativa da UERJ reserva vagas para estudantes de baixa renda, oriundos de escolas públicas, negros, indígenas, deficientes e filhos de policiais falecidos.

Ademais, um estudo sobre a desistência estudantil na Universidade Federal do Espírito Santo (UFES) mostrou que há uma taxa geral de desistência mais baixa entre os estudantes cotistas se comparada à dos não cotistas. (FORD, 2011, p. 67-68) Mesmo universidades privadas que instituíram programas de ação afirmativa têm obtido resultados bastante positivos. Por exemplo, na Pontifícia Universidade Católica do Rio de Janeiro (PUC-RJ), a maioria dos estudantes cotistas se encontram entre os $10 \%$ dos melhores alunos. (TREVIÑO GONZÁLEZ, 2010, p. 132) Além disso, um estudo do governo sobre o ProUni mostrou que a taxa de desistência dos estudantes bolsistas na zona oeste do Rio de Janeiro foi similar à média nacional. (AMARAL; OLIVEIRA, 2011, p. 21-42)

Em suma, o uso bem-sucedido de políticas de ação afirmativa no Brasil pode servir como uma inspiração para que outros países latino-americanos também melhorem antigos padrões de desigualdade racial em meio à retórica oposicionista que acredita na existência de uma democracia racial. Mais especificamente, assim como o resto da América Latina, o Brasil tem encontrado resistência às ações afirmativas sob o argumento de que a fluidez da identidade racial e a mistura racial iriam impedir a efetiva implementação dessas políticas. A esse respeito, uma análise do discurso brasileiro de miscigenação racial e formação da identidade pode oferecer mais elementos para países latino-americanos que buscam superar os obstáculos ideológicos e raciais às ações afirmativas. A afirmação da identificação racial nos censos oficiais oferece um marco analítico útil para se discutir como as presunções latino-americanas sobre fluidez racial podem coexistir com a prescrição de uma ordenação racial, de modo que as políticas de ação afirmativa possam ser implementadas efetivamente.

\section{Os desafios do recenseamento e de identidade para o cumprimento do direito antidiscriminatório}

Tendo em vista como, ao longo da história, o Estado tem manipulado os dados do censo relativos à raça para sub-representar a presença de pessoas de ascendência africana no Brasil (como detalhado nos capítulos 2 e 3), as organizações 
brasileiras de justiça racial têm buscado atuar mais diretamente nas maneiras pelas quais o discurso da suposta democracia racial impede uma averiguação precisa da demografia racial. No Brasil, os últimos censos usaram os termos para cor: "branco", "amarelo", "pardo" e "negro". Embora os censos regulares brasileiros usem o termo cor, as categorias de cor utilizadas correspondem diretamente a categorias raciais. A cor amarela destina-se à categoria racial "asiático", enquanto a cor negra se refere a pessoas de ancestralidade africana, "pardos" representa as pessoas com ancestralidade africana e europeia. A única categoria racial explícita no censo brasileiro de 1991 foi a “indígena”, em referência às populações nativas.

Demógrafos notaram que desde que o censo brasileiro instituiu a autodeclaração para coletar dados raciais em 1950, um número significativo de indivíduos mudou sua classificação racial de um censo para o outro. As alterações raciais apresentam um padrão específico, qual seja, uma grande parte das pessoas que se classificaram como negros, no censo de 1950, reclassificou-se como pardo no censo de 1980. (CARVALHO et al., 2004, p. 331-343) Padrões de reclassificação similares ocorreram nos recenseamentos dos anos seguintes.

Estudos sociológicos de outros conjuntos de dados no Brasil, com dados raciais tanto dos respondentes como dos entrevistadores, examinaram mais de perto a prática da fluidez na classificação racial e notaram que o "embranquecimento" corresponde a um padrão muito específico. Em um estudo de Edward Telles, $79 \%$ das vezes entrevistadores e respondentes escolheram inequivocamente a mesma classificação de cor para o respondente. (TELLES, 2002, p. 415-441) Enquanto as pessoas que se encontram na parte mais clara do espectro de cor tendem a ser classificadas de forma consistente, a ambiguidade é maior entre as pessoas que estão no lado mais escuro do espectro de cor. Mas até a ambiguidade tem seus limites. Entrevistadores tendem a embranquecer a classificação de pessoas com alto grau de educação formal e autodeclaradas pardas, em especial quando elas vivem em regiões com predominância de negros.

Em contraste, existe muito mais consistência na classificação de brancos que vivem em regiões com predominância de brancos. Ademais, o alto grau de escolaridade tem o mesmo efeito branqueador. No caso dos homens mais escuros, todavia, o alto nível de educação formal não altera a classificação de cor. São as pessoas mais claras que vivem em áreas com predominância não brancas as que apresentam maior tendência de branqueamento. Em resumo, o discurso da 
democracia racial, teoricamente, permite a qualquer pessoa se embranquecer, mas, na prática, as normas sociais predeterminadas limitam essa possibilidade. Pareceria que apenas em regiões onde poucos "brancos de verdade" vivem (como o Nordeste), os afrodescendentes de pele clara e alto grau de educação formal estariam socialmente permitidos a se embranquecerem estatisticamente. Quando os "brancos de verdade" predominam em uma região (como o Sul), existe pouca flexibilidade para pessoas visivelmente afrodescendentes se embranquecerem, independentemente da tonalidade de sua pele ou situação educacional. Esse padrão é ainda mais forte para homens afrodescendentes, talvez como resultado da sexualização das mulheres afro-brasileiras em combinação com o emprego ostensivo de estratégias para parecerem brancas, como alterações no cabelo, maquiagem e delineadores de lábios. (CALDWELL, 2007, p. 59-65, 90-106)

Similarmente, o embranquecimento intergeracional de crianças segue um padrão racializado específico. A Pesquisa Nacional de Amostragem por Domicílio do Instituto Brasileiro de Geografia e Estatística, em 2005, mostrou que um pai ou mãe não brancos, com ensino médio ou fundamental, provavelmente não embranquecerá sua criança tida com um(a) parceiro(a) branco(a). (SCHWARTZMAN, 2007, p. 940-963) Em geral, é nos raros casamentos inter-raciais entre pessoas com alto grau de educação formal que uma criança é embranquecida. Os casamentos inter-raciais, por si só, não garantem a regra de "uma gota de sangue branco" para embranquecer uma criança mestiça. Mas é o nível educacional de um casal inter-racial que facilita o embranquecimento.

Os estudos da maleabilidade das categorias de raça e cor no Brasil demonstram que outros fatores, que não a raça, também influenciam a escolha da categorias de "cor" no censo, constatando-se que a efetiva fluidez racial é restrita às pessoas de pele mais clara com alto nível educacional. Para aquelas com inequívoca pigmentação e características branca ou negra, a classificação racial é mais fixa e polarizada. De fato, mesmo aqueles estudos que examinam a grande quantidade de categorias informais de cor que existem no Brasil têm concluído que, na prática, as variações estão todas centradas na tentativa de denotar mistura racial, ao mesmo tempo em que mantêm polarizados os significados de branquitude e negritude. (SANJEK, 1971, p. 1126-1143; SILVA, 1996, p. 79-95)

Por essa razão, os ativistas brasileiros que lutam pela justiça social promoveram uma campanha, em 1991, pela inclusão de uma categoria específica para designar ancestralidade africana em detrimento de uma categoria de cor mestiça. (NOBLES, 2000, p. 146-162) Embora a solicitação para eliminar a categoria 
racial "mestiça" tenha sido rejeitada, os organizadores também promoveram uma campanha publicitária para encorajar os respondentes a evitarem a categoria "mestiça" e optarem pela categoria "negro". Essa campanha se chamava "Não deixe sua cor passar em branco: responda com bom senso", e o Instituto Brasileiro para Análises Sociais e Econômicas (Ibase), uma Organização Não Governamental que sistematicamente compila e distribui estatísticas sobre disparidades raciais no mercado de trabalho, ajudou a organizá-la. A campanha foi motivada pela preocupação que os brasileiros frequentemente apresentam sobre sua cor de pele, sendo que o desconforto de ter origens africanas faz com que os mesmos escolham categorias de cor mais claras por ocasião dos censos. A campanha por mais pessoas que escolhem a categoria "negro" de forma adequada foi montada para produzir dados socioeconômicos mais confiáveis sobre negros e, assim, ajudar na mobilização do movimento por justiça racial. Embora a campanha tenha sido bem-sucedida no que tange ao aumento da consciência do conteúdo político da identificação racial, as pessoas de descendência africana não optaram em massa pela categoria "negro" no censo. A incapacidade de reunir os recenseadores para uma sessão de treinamento sobre como abordar a questão raça e cor também pode ter atrapalhado a campanha.

O resultado do censo de 1991 apontou um leve aumento no número de brasileiros que usaram a categoria "pardo", em comparação aos números do censo de 1980, e uma leve diminuição no número de brancos. A categoria "negro" se manteve praticamente inalterada. (BRASIL, 1991) Ainda que em termos quantitativos a campanha tenha sido insignificante, seus organizadores alegam que foi uma vitória fazer com que os responsáveis pelo censo oficial brasileiro declarassem publicamente que repensariam as categorias de cor para os censos futuros, de modo a refletir o número de pessoas com ancestralidade africana de maneira mais precisa. (NOBLES, 1997)

Enquanto o censo de 2000 manteve as mesmas categorias de cor usadas nos anos anteriores, pela primeira vez em cinco décadas o número da população de pardos diminuiu, enquanto as populações branca e negra experimentaram um aumento. Em 2010, a população de pretos e pardos continuou a aumentar. A população negra aumentou de $6,2 \%$ para $7,6 \%$, enquanto a população de pardos aumentou de $38,4 \%$ para $43,1 \%$. Em contraste, os números da população branca diminuíram pela primeira vez desde que os censos começaram a ser realizados no Brasil, de 53,7\% da população, em 2000, para 47,7\% da população, em 
2010. O sociólogo Edward Telles sugere que as alterações censitárias nos percentuais de categoria de cor indicam que o "sistema de classificação racial brasileiro está se tornando cada vez mais bipolar" devido à influência do movimento negro e da globalização da cultura negra com a circulação mundial da música e filmes da diáspora africana, que encorajam uma identificação não ambígua com a negritude. (TELLES, 2004, p. 101) A reflexão de Telles também é corroborada por recentes estudos etnográficos que demonstram a crescente tendência de pessoas com ancestralidade africana no Brasil se identificarem como negras, realizando uma escolha política que reconhece a formação de uma identidade especificamente racial em resposta à consciência da discriminação racial. (CALDWELL, 2003, p. 40; SILVA, 2007, p. 69; FERREIRA, 2002, p. 69-86; HOSTEN, 2007, p. 21-29)

Além do mais, a promoção de uma identidade racial política negra não é exclusivamente o trabalho de movimentos por justiça social. Por exemplo, uma ala progressista da Igreja Católica no Brasil, a Pastoral Negra, está envolvida com a criação de uma consciência católica antirracista por meio de uma teologia, liturgia, prática pastoral, treinamento, oficinas e mídia. (BURDICK, 2004, p. 19, 48-53) Mesmo nas comunidades protestantes, que são comumente vistas como hostis às invocações de orgulho negro, etnógrafos encontraram comunidades de protestantes afrodescendentes e pobres devotos da escrava Anastácia, que formularam uma identidade negra empoderada pela figura histórica de uma escrava virtuosa (SHERIFF, 2001, p. 10) e o discurso de igualdade da Igreja Pentecostal. (BURDICK, 1998, p. 127-147, 161-180) Ademais, etnógrafos têm documentado, nas favelas do Brasil, não somente a existência de uma vibrante consciência racial negra entre os habitantes, mas também de um enfoque binário, em vez de uma abordagem racial fluida, como bem podemos ver na frase "Se você não passa por branco, você é preto". De fato, o uso de categorias de cor variáveis foi explicado pelos moradores da favela simplesmente como uma questão de cortesia universalmente aceita para manter a harmonia racial, ainda que haja um entendimento implícito de que "existem apenas duas raças” (SHERIFF, 2001, p. 58)

Como um acadêmico brasileiro declarou de modo franco:

Não há dificuldade intransponível em estabelecer um sistema padrão e funcional de classificação racial no Brasil porque nós nos classificamos voluntariamente como negro, branco, pardo, amarelo e indígena quando 
entrevistados pelos censos oficiais e também somos facilmente identificados com base nessas categorias por outros cidadãos, pela polícia e pelo sistema de justiça. Nós não temos problemas em saber quem é negro, pardo, branco, amarelo ou indígena. (SANTOS, 2006, p. 30-48)

Portanto, afirmações de que os brasileiros enfrentam problemas para se afirmar racialmente são um exagero.

Ao passo que é certo que a ideologia racial latino-americana do Brasil exalta as virtudes da suposta capacidade de ser flexível na hora de declarar a cor ou a identidade racial, essa exaltação coexiste com a capacidade de impor determinadas consequências àqueles identificados como não brancos. Por essa razão, Seth Racusen declarou acertadamente que "se numerosos atores públicos e privados podem rotineiramente tomar decisões discricionárias com propósitos discriminatórios, por que não seria possível para esses atores fazer determinações para promover políticas antidiscriminatórias?”. (RACUSEN, 2009, p. $89,92)$ O ponto de Racusen é que enquanto pode haver variação no modo com que os não brancos, que se parecem entre si, se identificam racialmente (negro versus pardo), o que é mais importante para a administração de uma política de ação afirmativa é a estrutura social que diferencia a condição de ser branco e a de não ser branco, com o propósito de influir no status social e nas oportunidades. Isso porque uma política de ação afirmativa procura interferir nas exclusões que configuram o status quo racial. A fluidez das categorias é irrelevante quando comparada ao significado da hierarquia racial particular, nas quais as categorias se alinham entre si. De fato, servidores públicos brasileiros têm administrado programas de ação afirmativa de forma criativa, operando em meio à fluidez racial por meio do recurso a várias combinações substitutas que indiquem a condição de não negro, tais quais ter cursado ensino médio em escola pública, ser de baixa renda, juntamente com autodeclaração racial de negritude, fotografias e entrevistas para determinar se os candidatos estão aptos a participar do programa. Por conseguinte, a afirmação de que ações afirmativas são uma importação imperialista dos EUA não pode efetivamente ser aplicada no contexto racial da América Ibérica, como o caso brasileiro tem mostrado. Desse modo, a experiência brasileira, até agora, deve servir como um importante guia para o resto da América Latina. 